\title{
DEVELOPING AN INNOVATIVE PROGRAM FOR FIRST YEAR ENGINEERING STATISTICS STUDENTS AT AN OPEN DISTANCE UNIVERSITY
}

\author{
Richard Naidoo, IODL, CGS, Mosia Ngaka, Mechanical Engineering, CSET, Unisa, South
}

Africa

\section{Abstract}

A study was performed on a first year industrial engineering statistics course to improve the statistics pass rate. Statistics is a requisite for other engineering courses. The pass rate for the statistic course was below 50\%. The primary purpose is to enable learners to build a capacity to comprehend module content and establish a deeper level of learning that will enable learners to achieve goals and objectives of T\&L lessons. An intervention program was instructionally designed to develop a personalized and differentiated learning process that breaks down lessons into lower and basic cognitive components, for struggling learners. The program improves e-learning lessons to a complex higher cognitive level and advances challenging activities for excelling students. Forty students were considered for the study. Moore's theory of transactional distance was used as a theoretical framework. A quantitative method was used to analyse the data. The data consisted of assignment scores. Hypothesis testing at a 95\% level of significance suggests that the intervention program made an impact. The overall pass rates improved by $25 \%$.

\section{Introduction}

The first year statistics course in the engineering department at an ODL university produces pass rates below $50 \%$.

Pinker (2002) suggests students beliefs might help or hinder learning depending on their consistency or discrepancy with what is lectured. From the perspectives, ODL lecturers have been interested in student's preconceptions and misconceptions so that content design and content instructional design can be effected. Fisher (1985) believes misconceptions emanate from strong word association, confusion, conflict, or lack of knowledge. The categories of misconceptions are describes as follows: 
- $\quad$ students are at variance with normative conceptions held by statistics experts;

- $\quad$ students tend to be pervasive (shared by many different individuals);

- $\quad$ students are often highly resistant to change.

Consequently, statistical lecturing methods and models have to be developed. Lawrenz (1986) and Smith and Anderson (1984) suggest statistics lecturers engage with numerous examples of how to identify misconceptions by students and strategies to change them. A common view is to begin the lectures with students' ideas and then design engagement lectures notes (Engel Clough \& Wood-Robinson, 1985).

Peters et al. (2014) suggest there is evidence that blended classroom models can be effective only when the online elements are active rather than passive. Undergraduate students in blended classroom settings had better assessment outcomes than purely online or face-toface classes. The reason being that blended courses in which the students are spending their time online solving problems, learning at their own pace. Half-teaching time was on eLearning. It has a more positive learning impact than both face-to-face do only and purely online only (Peters et al. 2014) do.

A study of previous courses suggests content comprehension was a challenge for first year module students. It necessitated a program that student needed a differentiated approach and different learning techniques and offering the best from both components of a blended learning course. It is apparent that for engineering students pacing is needed and learning must be possible on more platforms than just on the LMS (Learning Management System). Therefore, a T\&L approach that provides a better control to the learner and is supported with online resources is indispensable (Peters, 1994). Thus, an active technology integrated T\&L approach is critical for throughput improvement.

Learning may mean acquisition of knowledge and deepening of understanding of concepts. Learning includes acquisition and improvement of both technical and interpersonal skills and/or development of desired attitudes and values. Understanding, skills, attitudes and values are all highly subjective constructs. Studies have shown that the more students work in cooperative learning groups the more they learn, the better they understand what they are learning, the easier it is for them to remember what they learn (Johnson et al., 1998a; 1998b; 1998c). Springer et al. (1999) meta-analysed the research for college-level science, engineering and technology and found significant effects on students' persistence and achievement in these fields and positive attitudes toward their education.

Therefore, a system with the ability to adapt intelligently to goal, tasks, interests and other features of individuals and groups of users, is an ideal engineering technology education medium. In an ODeL (Open distance eLearning) institution, access is given to all potential 
students with varying school mathematics grade 12 scores and therefore different competencies of the basic engineering modules such as mathematics and science. Some student have poor grades, while others have very good grades. This in the teaching and learning process, it is not possible to treat all students in the proliferating range of elearning users with very different prior knowledge of the domain, backgrounds, learning styles, interests and preferences, with the "one size fits all" approach. Therefore, adaptation of the learning process and assessment is indispensable.

The power of this innovation is in matching the educational content and the complexity or simplicity of the material, with the learning style of the learners and considering the underlying pedagogical principles. The effect of the combination of strategies is observed and comprehended by analysing the assignment scores of learners and therefore, making a decision to adapt learning content by increasing the complexity of the problems or simplifying content. Since the learning styles are not static (Siadaty \& Taghiyareh, 2007), assessment, alignment and adaptation is done continuously throughout the learning period i.e. semester or year.

Connected to Learning Styles is Statistical Cognition. Ruth Beyth-Marom et al. (2008) defined statistical cognition as the processes, representations, and activities involved in acquiring and using statistical knowledge. The issues of statistical cognition can be described as follows:

- Descriptive: students acquire and use statistical knowledge and how they think about statistical concepts.

- Normative: how students should think about statistical concepts and a standard to which our performance is usually compared.

- Prescriptive: How to close the gap between the descriptive (the "is") and the normative (the "should").

The study is guided by the learning styles and Statistical cognition as defined by BeythMarom et al. (2008).

\section{Theoretical Framework}

Introduced in the early 1970s, is the theory of transactional distance by Michael Moore. Moore recognized the limitation of the structure of the independent learning package by including dialogue as a second variable. Moore's theory of transactional distance is intuitively appealing and moves the field toward the realization of a pedagogical theory. According to Moore (1991), transactional distance is pedagogical and necessitates "special organizations and teaching procedures" composed of two variables (clusters, dimensions?), i.e. structure and dialogue (Moore, 1991; Moore \& Kearsley, 1996). Structure 
reflects the course's design and is largely a function of the teaching organization and communications media employed.

On the other hand, dialogue is also associated with the medium of communication and may include either real two-way communication or Holmberg's internal didactic conversation. In Moore's theory, the most distant program has low dialogue and low structure while the least distant has high dialogue and high structure (Moore, 1993). The innovation program applied Moore's pedagogical variables of transactional distance. The innovation works on structure as it relates to course design and communication media employed. It is also deals with dialogue, for the engagement between student and instructor is bound to increase.

\section{Methodology}

The study is focused on first year engineering student, who have taken engineering statistics for the semester. Analysis was performed on the results of the first assignment to measure the impact of the innovation on student performance. Adequate supports was provided for students with different learning styles. Fahy and Ally (2002) found that students with different learning styles have different preferences for support. The difficulty level of the material is set to match the cognitive level of the learner, so that the learner can both attend to and relate to the material.

Cognitive description is applied on the pre-test scores and student are grouped according to their performance. Poor performing students are placed on a pacing and an instructional scaffolding-teaching program and excelling students are placed on an adaptive learning and gradual release of responsibility program. (See Figure 1). 


\section{Developing an Innovative Program for First Year Engineering Statistics Students at an Open Distance University}

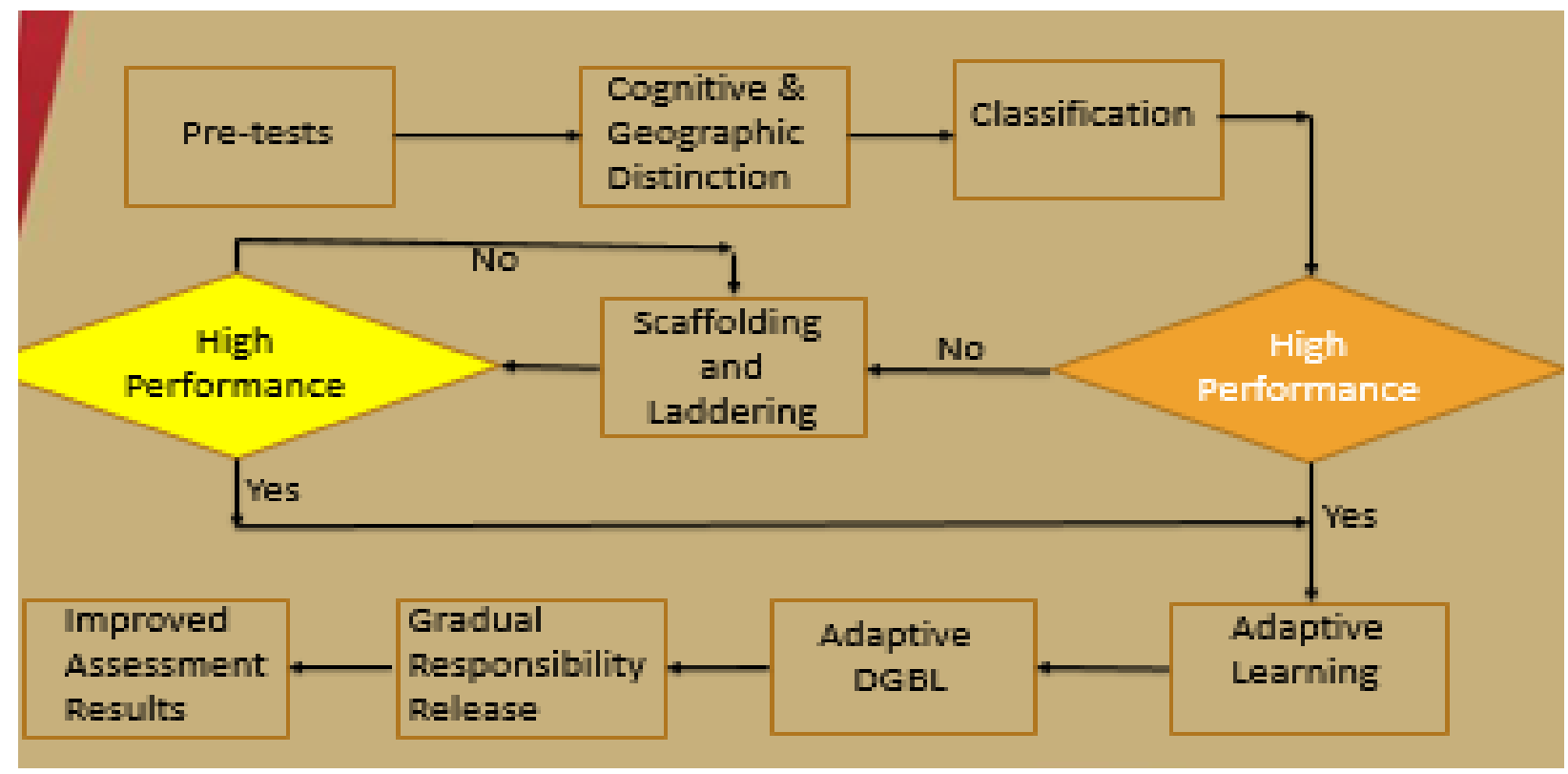

Figure 1. Intervention model

Applied techniques for mapping this approach into practice are providing a pre-test, breaking off the learning material into small pieces, sequencing the material from easy to more difficult and providing links for further exploration to fulfil this characteristic of sensation seeking learners. This approach is implemented by applying methods such as providing the summary and outline of the content, chunking the educational material into meaningful groups and giving the learners the opportunity to revisit topics to strengthen their retention. In order to evaluate the proposed program the instructors matched the educational contents with the learning style of the learners along with considering the underlying pedagogical principles.

Table 1: A summary of the questions and objectives

\begin{tabular}{|c|c|c|}
\hline Research Question & Hypothesis & Prediction \\
\hline Does, the matching of & Matching the educational & If I match module contents \\
\hline $\begin{array}{l}\text { Educational contents with } \\
\text { learning styles of learners and } \\
\text { underlying pedagogical } \\
\text { principles, affect learners } \\
\text { performance outcomes? }\end{array}$ & $\begin{array}{l}\text { Contents with the learning styl } \\
\text { of the learners along with } \\
\text { considering the underlying } \\
\text { pedagogical principles, affects } \\
\text { the performance of the } \\
\text { students in terms of learning } \\
\text { outcomes. }\end{array}$ & $\begin{array}{l}\text { eWith the learning style of the } \\
\text { learners along with considering } \\
\text { the underlying pedagogical } \\
\text { principles, learner's performance } \\
\text { outcomes will improve. }\end{array}$ \\
\hline
\end{tabular}

The experimental group were provided with the personalized contents based on their learning styles whilst the control group was given the non-matched contents, originally designed for that course. The limitations of the study are that: 
- $\quad$ Learning styles are not static, initiating the T\&L framework once (per group) when learners first use the system, might not be adequate.

- It is possible that learners are not assessed as effectively.

Application of teaching technologies, learning objects and instructional support media tools to enable learning possibilities, whenever, where ever and on whatever device student have access to at a point in time, is key to the innovation employed. This strategy consists of a representation of learning materials that the learner can engage and includes a set of domain concepts such as facts, lessons and activities organized to form a kind of a semantic network as stipulated by Siadaty and Taghiyareh (2007). At this stage numerous instructional support material such as OERs, LO, MOOCs from other institutions, were used.

\section{Results}

Results of the impact of the innovation on student's performance are displayed below. S1 and S2 represent semester one and semester two assignment scores. There is a general increase in pass rate for the years 2015 to 2018. These results imply that the innovation has a positive impact on the combined learner's performance. Note that these results represent both excellent students and students who were struggling in the beginning of the semester.
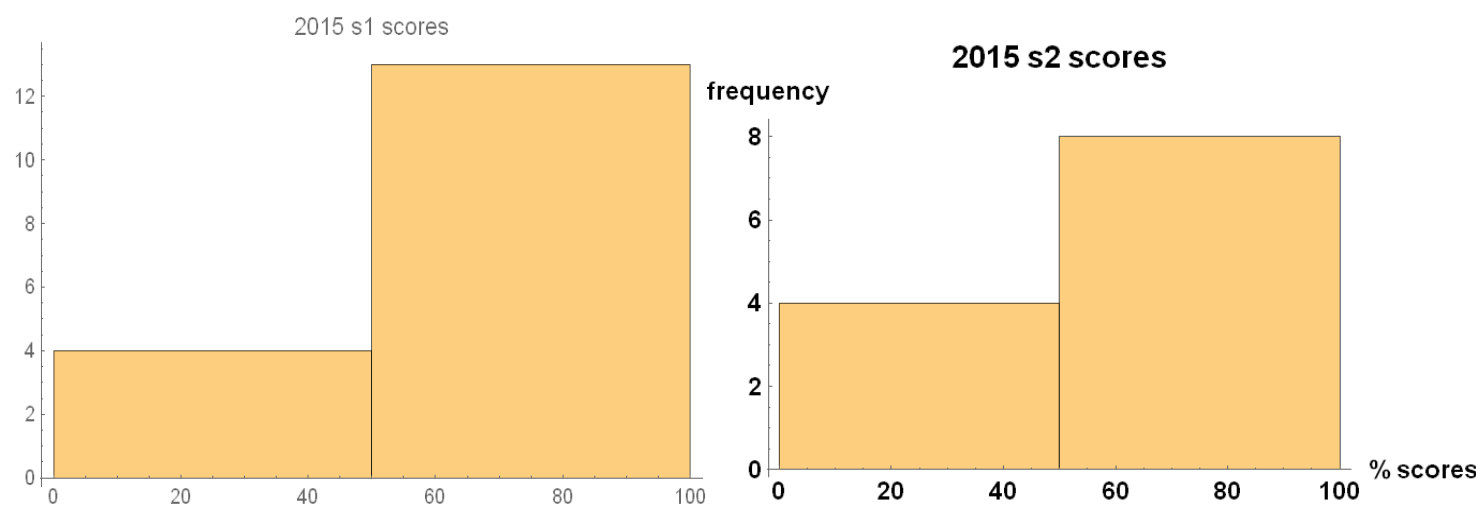

Figure 2. Assignment scores for S1 and S2 in 2015

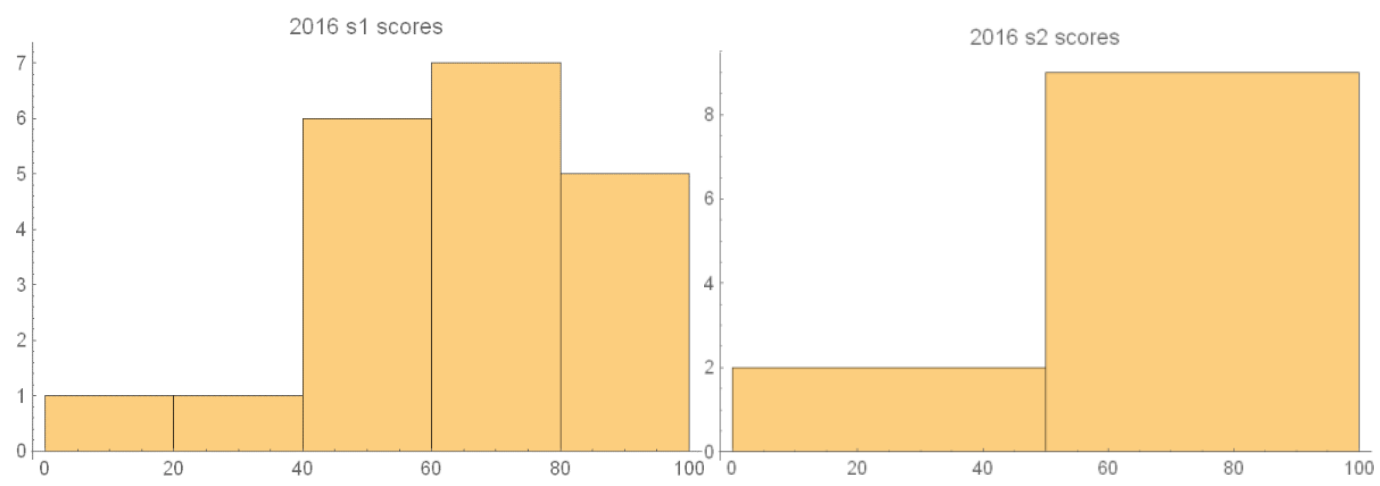

Figure 3. Assignment scores for S1 and S2 in 2016 


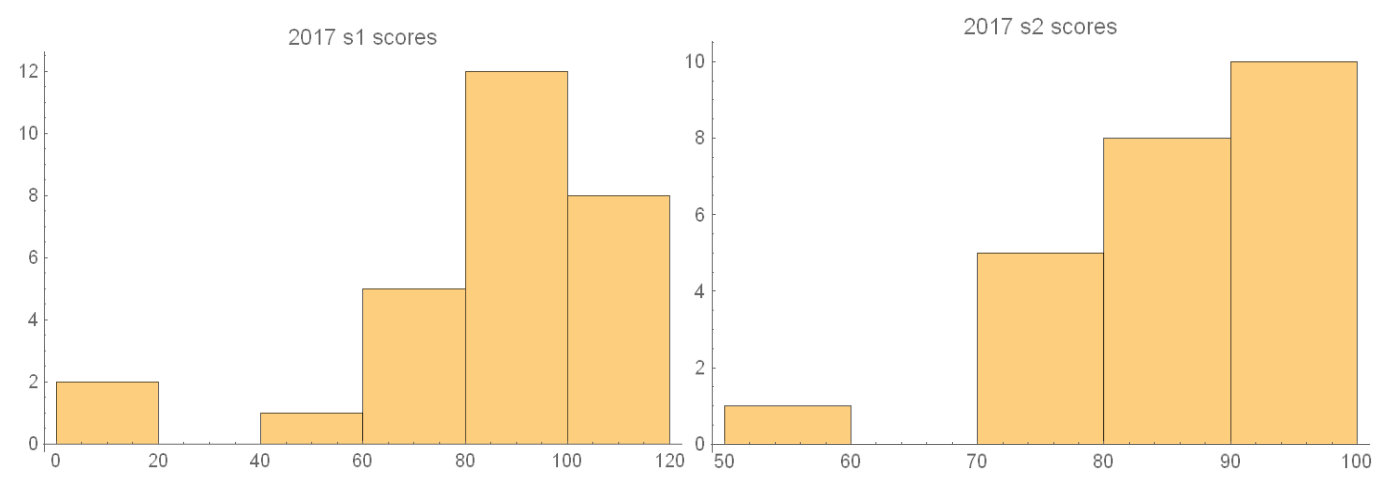

Figure 4. Assignment scores for S1 and S2 in 2017

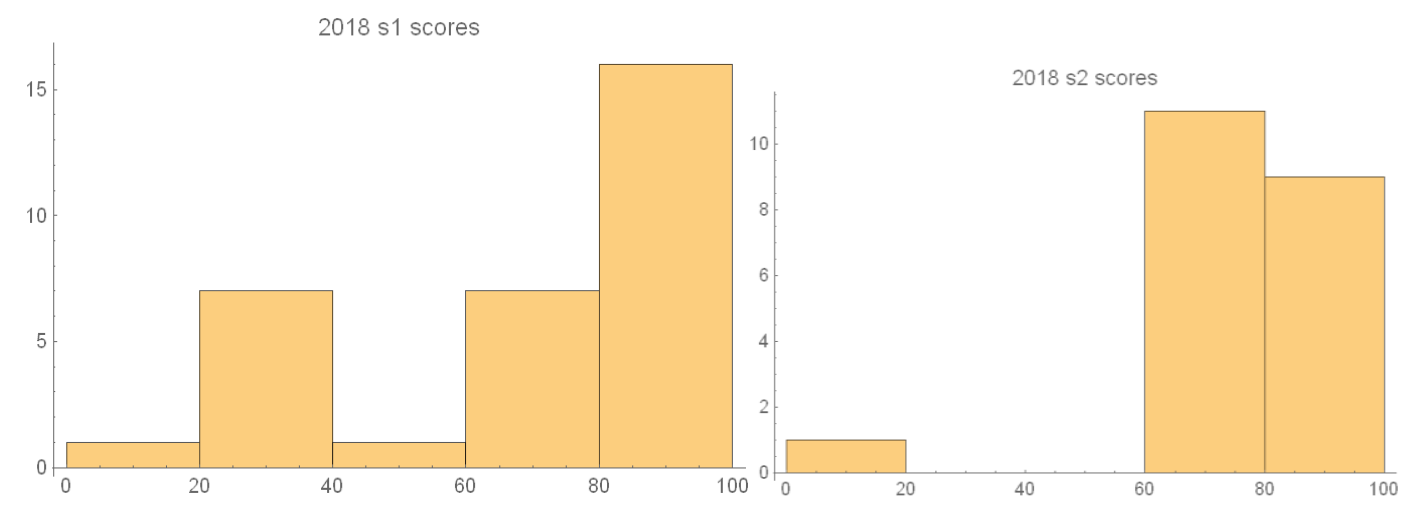

Figure 5. Assignment scores for S1 and S2 in 2018

In the beginning of the program, there are clearly two homogenous groups of student, i.e. a big group of struggling students and another big group of good performance students. In the subsequent years, student performance began to stratify, and there are new groups formed, i.e. a small group of utterly struggling students and numerous groups of students with improved performance and a sizeable group of excelling students. Hypothesis testing at the 95\% probability indicates that during the years 2015 to 2018 students were performing better after the intervention. The students were performing better during the second semester assignments than the first semester assignments. The intervention was instituted during the first semester and during the first assignments stage.

\section{Discussion}

An intervention of a teaching program which was instructionally designed to develop personalized and differentiated learning process for students, through breaking down lessons into lower and basic components, for struggling learners, and improves lessons to a complex high level and challenging activities for excelling students, proved to have produced positive results. First, the struggling students group is reduced gradually and the excelling student's group size is increased. Second, the two homogenous groups of good performance and struggling learners gradually disappears and they are replaced by numerous and smaller groups of learners performing above $50 \%$. 
Towards the end of the study, i.e. 2017/2018, it becomes apparent that the group of excelling students increased and that of struggling students decreased significantly. It is also clear that more learners have improved their performance above $50 \%$ and a large group is in the category of excellent performing students was noted. The innovation introduced has improved student performance gradually and increased the number of excelling students. In general, the student success rates has been increased and performance improved for a large number of learners approximately $25 \%$.

\section{Conclusion}

It is evident that this innovation model integrates Moore's pedagogical variables, i.e. structure and dialogue, and builds a new conception for the four component of the intelligent tutor system (ITS), as inspired by Bloom's learning theory (Springer et al., 1999).

The model content design included Beyth-Marom et al. (2008) categories of cognition and descriptive, normative and prescriptive.

The resultant is that student have an integrated view of the instructor's responsibilities (Petocz \& Reid, 2003). They expect lecturers to be a catalyst for their learning and help them to change their view of the world of teaching and learning statistical content. Therefore, lecturers are seen to open student's minds to new possibilities and better performance.

This conception of teaching and learning is different from the common and general method, because it focuses on helping students to develop a higher level of comprehension of subject matter content. Therefore, the innovation model implemented confirms that it is no more possible to treat all students in the proliferating range of e- learning users with very different prior knowledge, backgrounds, learning styles, interests and preferences, with the one-size-fits-all approach. It is thus, confirmed that when module contents is matched with the learning style of the students and the cognitive categories ,along with considering the underlying pedagogical principles, learner's performance outcomes will improve, and therefore the hypothesis is confirmed.

\section{References}

Engel Clough, E., \& Wood-Robinson, C. (1985). How secondary students interpret instances of biological adaptation. Journal of Biology Education, 19, 125-130.

Fahy, P. J., \& Ally, M. (2002). Student Learning Style and Asynchronous ComputerMediated Conferencing (CMC) Interaction. The American Journal of Distance Education, 19(1), 5-22. 
Fisher, K. (1985). A misconception in biology: Amino acids and translation. Journal of Research in Science Teaching, 22, 53-62.

Lawrenz, F. (1986). Misconceptions of physical science concepts among elementary school teachers. School Science and Mathematics, 86, 654-660.

Moore, M. G. (1991). Editorial: Distance education theory. The American Journal of Distance Education, 5(3), 1 - 6.

Moore, M. G. (1993). Theory of transactional distance. In D. Keegan (Ed.), Theoretical principles of distance education (pp. 22-38). New York: Routledge.

Moore, M. G., \& Kersley, G. (1996). Distance Education: A systems view. New York: Wadsworth.

Peters, O. (1994). Distance education and industrial production: A comparative interpretation in outline (1973). In Keegan, D. (Ed.), Otto Peters on distance education: The industrialization of teaching and learning (p. 107-127). London: Routledge.

Petocz, P., \& Reid, A. (2003). Relationships between Students' Experience of Learning Statistics and Teaching Statistics. Statistics Education Research Journal, 2(1), 3-21. Retrieved from https://iase-web.org/Publications.php?p=SERJ_issues

Pinker, S. (2002). The blank slate: The modern denial of human nature. New York: Viking Penguin.

Beyth-Marom, R., Fidler, F., \& Cumming, G. (2008). Statistical Cognition: Towards Evidence-Based Practice in Statistics and Statistics Education. Statistics Education Research Journal, 7(2), 20-39. Retrieved from https://iaseweb.org/documents/SERJ/SERJ7(2)_Beyth-Maron.pdf?1402525008

Siadaty, M., \& Taghiyareh, F. (2007). PALS2: Pedagogically Adaptive Learning System based on Learning Style. Paper presented at the $7^{\text {th }}$ IEEE International Conference on Advanced Learning Technologies (ICALT 2007)

Smith, E. L., \& Anderson, C. W. (1984). Plants as producers: A case study of elementary science teaching. Journal of Research in Science Teaching, 21, 685-698 